239. LefCruRfs on Aphasia. Bramwell (Edinburgli Medical Journal, July to December, 1897).

These lectures are an elaboration of those given by the author in his course on medicine. He makes the usual divisions of aphasia into (a) word deafness, (b) word blindness, (c) motor vocal aphasia (aphemia), (d) motor writing aphasia (agraphia), and procceds to describe the chief characteristics of each variety. The close connection between the centre of auditory word memories and the speech centre and that between the centre for visual word memories and the writing centre is emphasized. Speaking of word deafness, he suggests that the cliaracter of the lesion, whether irritative or destructive, is of importance, as where it is only irritative there may be paragraphia or paraphasia, instead of complete loss of power to write and to speak. When the centre for visual word menories is destroyed, there may be still ability to write through the revival of memories of novements presented in the hinesthetic centre for writing movements, but this power can liardly extend further than to the production of syllables and short words, not to complete sentences. It is certain that destruction of the vistual speech centre does not produce paralysis of the movement of the hand and arm, but it is a question whether or not, under the circumstances, the finer movements, such as piano playing. etc., do not suffer to some extent, and observations on this point are necded.

The author is of the opinion that a separate writing speech centre does not exist, but that the centre for writing movements is included in the psychomotor centre for movements of the hand and arm. Whether the kinesthetic memories of the movements made use of in w-iting are stored up in the same region from which the motor impulses emanate, or elsewhere, is uncertain. Speaking of other varieties of sensory aphasia, it is suggested that in the blind, who read by sense of touch, as the result of a lesion "tactile aphasia" may be produced, and it is urged that physicians to blind asylums investigate the matter.

The aplasic symptoms due to interruntion of the connecting and commissural fibres passing between the different speech centres are next considered, and after this follows a discussion as to the relative activity of the corresponding speech centres in the two hemispheres of the brain. While one side of the brain (the leit in right-lianded people) contains the leading or "driving" centres. the action of the centres upon the opposite side should not be underestimated, as it is douhtless important. In support of this point, a number of facts are mentioned, and interesting suggestions are made. The question of blood supply to the different centres is taken up, and it Is pointed out that most of them are situated about the boundary lines of regions supplied by different centres. and as these boundaries vary soincwliat in different brains. we may have here an explanation of the different symptoms resulting from the plugging of a certain artery in different cases. Lastly follows a discussion of the physiolony of speaking and writing. and the development and education of the different centres concerned in these processes. This is one of the most interesting and instructive parts of the course. The lectures are clearly and pleasantly written. and give an excellent résumé of the suhject. At.r.s.

240. ZUR LEHRF VON DER GIEICHSEITIGFN HEMIPLEGIF MFI CFRFBRALFN ERkRANRUNGFin (A Contrihution to the Study of Collateral Hemiplegia in Cerebral Diseases). N. Ortner (Deutsche med. Wochenschrift, 23. 1897. p. 372).

Ortner mentions a valuable diagnostic sign in cases of collateral hemiplegia, $i$. e., those in which the paralysis is on the same side 
as the cerebral lesion. He reports two cases of left-sided hemiplegia, in each of which he correctly made the diagnosis of a left-sided cerebral lesion, because the degree of the respiratory movements of the right side of the thorax was much below normal, while on the left sicle the movements were not affected. He acknowledges that in rare cases of contralateral cerebral hemiplegia differences in the respiratory movements of the two sides of the thorax are not found. It is not the condition of the extremities, but that of the respiratory muscles which is of decisive moment for the localization of the lesion in cerebral hemiplegia.

After mentioning and rejecting the various theories advanced to explain hemiplegia existing on the side of the cerebral lesion, Ortner accepts the views of Pinneles. There is not a true paralysis of the limbs on the same side as the lesion in these cases, but a relaxation of the muscles, and in the limbs of the side opposite to the lesion there are manifestations of cerebral irritation, such as apparently voluntary movements of defense. As sucl symptoms of irritation are absent in the limbs on the same side as the lesion, the appearance of paralysis is produced. In none of thirty-eight cases of collateral hemiplegia, with autopsies, taken from the literature was there any statement of a lesion of the internal capsule. and in all these cases the lesion. from its location, was well adapted to cause sigus of irritation in the opposite half of the body.

Collateral hemiplegia is comparatively frequent in hæmatoma of the meninges or in internal hemorrhagic pachymeningitis, and the diagnosis of these conditions becomes possible in cases in which apparent paralysis of the limbs, and, possibly, also of the face, of one side offers a striking contrast to the normal movements of the respiratory muscles of the same side. Trephining in such cases should be done on the side on which the heniplegia is noted.

The observation of imperfect respiratory movements on one side will lead to a correct diagnosis of the side of the brain affected in cases in which bilateral symptoms of irritation or flaccid paralysis of the extrenities are present.

SPILLER.

\section{PSYCHOI,OGY AND PSYCHIATRY.}

2.41. A STrDy in AppFrception. W. B. Pillsbury (American Jour. of Psychology, 8, 1897, p. 315).

The author presents Wundt's views. In normal consciousness, at any time, some ideas will be found to be prominent and distinct, while others are vague and indefinite, gradually shading down to obscurity from "the point of clearest vision." Clearness of ideas is not the same as intensity of sensation, but intensity favors clearness, and clearness favors intensity. Degree of clearness varies inversely with the number of ideas simultaneously contained in the point of clearest mental vision. Preceding, accompanying and succeeding increase in the clearness of ideas there is a varying complex of sensational and affective phenomena, viz.. (I) increase of clearness in the idea directly before the mind. accompanied by the immediate feeling of activity; (2) inhibition of other ideas: (3) muscular strain sensations with the feelings connected with them, intensifying the primary feeling of activity: (4) the reflex of these strain sensations intensifying the idea apperceived. An idea never undergoes the peculiar increase in clearness when these phenomena are not present. The cliange of clearness is not like quality or extent and other attributes of sensation. It takes place while all external conditions remain the same. The whole circle of subjective processes connected with apperception Wundt calls "attention".

Passive apperception is present ( 1 ) at certain times when an idea 